\title{
Effects of Dual Task Training on Balance and Functional Performance in High School Soccer Players with Functional Ankle Instability
}

\author{
Kwang-II Kwak', Bum-Jin Choi ${ }^{2}$ \\ ${ }^{1}$ Rehabilitation Center, Gwang ju Plant, Kumho Tire, Gwangju; ${ }^{2}$ Sport Rehabilitation Center, Saenarae Hospitall, Gwangju, Korea
}

Purpose: This study was conducted to identify the effects of dual task training on balance and functional performance in high school soccer players with functional ankle instability.

Methods: Twenty high school soccer players with functional ankle instability were randomly assigned to a single task training group and a dual task training group. One participant who did not participate regularly in the training was excluded. The single task training group $(n=9)$ received balance training on an unstable surface. The dual task training group $(n=10)$ received balance training on an unstable surface and had to catch thrown balls during the balance training. Both groups were trained for 4 weeks, 3 days a week. The balance and functional performance of both groups was measured before and after training. Balance was measured using an anterior-posterior and medio-lateral balance. Functional performance was measured based on a figure-of-8 hop test, up-down hop test, and a single hop test. All data were analyzed by repeated two-way ANOVA tests.

Results: A time by group interaction effect was not observed in the medio-lateral balance test, figure-of-8 hop test, or single hop test $(p>0.05)$. A time by group interaction effect was observed in the anterior-posterior balance and up-down hop test $(p<0.05)$.

Conclusion: These results suggest that dual task training improved balance and functional performance better than single task training for some items.

Keywords: Dual task training, Functional ankle instability, Balance, Functional performance

\section{서 론}

기능적 발목 불안정성(functional ankle instability, FAI)은 반복적인 발 목 염좌에 의한 고유수용성감각 결손과 신경근 조절 능력 저하로 발 생하며, 운동선수와 비운동선수 모두에게 흔하게 발생한다. ${ }^{23}$ 기능적 발목 불안정성 환자는 관절의 정적 및 동적 지지 능력 상실과 주관적 인 발목의 휘청거림(giving way)을 느끼게 되며, ${ }^{4}$ 자세 조절 능력의 손 상으로 부상 위험이 증가하므로 적절한 치료적 중재가 필요하다.5-7

기능적 수행능력은 스포츠 활동 중 이루어지는 빠른 방향 전환과 안정된 착지 등을 성공적으로 수행할 수 있는 능력을 의미하며, ${ }^{8}$ 기능 적 발목 불안정성 환자에서 기능적 수행 능력 손상이 보고되었다.9 기 능적 수행능력 평가는 일상생활에서의 동작이나 운동에서 사용되는 것과 비슷한 동작 패턴을 기반으로 평가를 실시하며, ${ }^{10}$ 무릎이나 발목
손상 후 스포츠 활동 복귀를 위한 중요한 지표로 사용되고 있다."

발목 불안정성 회복을 위하여 발목 근력 운동, ${ }^{12}$ 고유수용성 훈 련, ${ }^{13}$ 균형 훈련, ${ }^{14}$ 상상운동, ${ }^{15}$ 등속성 운동, ${ }^{16}$ 발목구조 지지를 위한 테 이핑 요법 17 등의 치료적 중재가 시행되고 있으며, 발목 불안정성의 효 과적인 중재 방법에 대한 지속적인 연구가 진행되고 있다.

이중과제훈련은 운동과제와 인지과제를 동시에 수행하는 치료적 중재로 뇌졸중과 같은 신경학적 손상 환자의 운동 회복을 위한 중재 로 사용되고 있으며, ${ }^{18}$ 최근 정상인과 근골격계 환자의 균형과 자세 조절 향상을 위한 치료적 중재로 사용되고 있다. 이중과제훈련은 Ross 등 19 의 연구에서 단일과제훈련보다 정상 성인의 균형을 향상시 키며, Resch 등 ${ }^{20}$ 의 연구에서 운동선수의 자세 안정성에 영향을 미치 는 균형 향상에 효과적이라고 보고되었다. Daele 등ㄹㅇㅢ 연구에서 정 상인과 요통 환자의 자세 동요와 체간의 뺏뺏함을 감소시키는데 효 
과가 있다고 보고되었다.

이처럼 이중과제훈련이 정상인과 근골격계 환자의 자세 조절과 균 형 향상에 효과적이라고 보고되고 있으나 대부분 허리, 무릎 손상 등 의 환자를 대상으로 연구가 진행되어 자세 조절과 균형 유지에 많은 영향을 미치는 발목 손상에 관한 연구는 부족한 실정이며, 운동 선수 의 발목 손상 후 스포츠 활동 복귀를 위한 중요한 지표가 되는 기능 적 수행 능력 평가에 대한 연구도 부족한 실정이다.

이에 본 연구는 기능적 발목 불안정성이 있는 고등학교 축구선수 에 이중과제훈련을 적용하여 이중과제훈련이 기능적 발목 불안정성 운동선수의 균형과 기능적 수행능력에 미치는 영향을 확인하여 기 능적 발목 불안정성 환자의 물리치료적 중재를 위한 기초 자료를 제 공하고자 하였다.

\section{연구 방법}

\section{1. 연구대상}

본 연구의 대상자는 Docherty 등22이 제시한 발목 불안정성 설문지에 의해 기능적 발목 불안정성을 가진 것으로 판단된 고등학교 축구선 수 20명을 대상으로 하였다. 대상자는 모두 마지막 염좌가 발생한 후 3 개월 이상 경과되었으며, 최초 평가 시 골절이나 수술 병력이 있거나 부종이 있는 대상자는 제외하였다. 중재 중 규칙적으로 치료에 참여 하지 못한 1 명을 제외하였으며 단일과제훈련군 9 명, 이중과제훈련군 10 명을 대상으로 하였다.

\section{2. 실험방법}

1) 실험 절차

본 연구의 대상자들은 연구의 목적과 방법에 대해 충분한 설명을 들은 후 실험 참여에 자발적으로 동의하였으며, 광주광역시 $\mathrm{W}$ 스포츠재활 센터에서 2015년 10월 5일-31일까지 주3회, 총 4주간 운동을 실시하였다.

모든 대상자는 중재 전 스트레칭과 러닝으로 구성된 준비 운동을 20 분 동안 실시하였으며, 충분한 설명과 시범을 보여준 뒤에 훈련을 실시하였다. 단일과제훈련군은 첫째 주는 토구(Dynairball cushion senso, TOGU, German) 위에 두 발로 서기, 둘째 주는 토구 위에 두 발 로 서서 좌-우 체중 이동, 셋째 주는 토구 위에서 한 다리로 서기, 넷 째 주는 토구 위에서 앉았다 일어서는 균형 유지 훈련을 실시하였다. 이중과제훈련군은 단일과제훈련군과 동일하게 4 주 동안 토구 위에 서 각각 다른 동작으로 균형을 유지하는 단일과제훈련 동안 실험자 가 $5 \mathrm{~m}$ 거리에서 던진 공을 받게 하는 이중과제훈련을 실시하였다. 대상자에게 빨간색, 노란색, 흰색 3 가지 공을 무작위로 던진 후 빨간 공은 오른손, 노란 공은 왼손, 흰색 공은 양손을 사용하여 받게 하였 다. ${ }^{23}$ 공의 크기는 지름 $6 \mathrm{~cm}$, 무게 $70 \mathrm{~g}$, 스펀지 재질로 된 소프트볼을
사용하였다. 단일과제훈련군과 이중과제훈련군 모두 30 분 동안 6 세 트의 운동을 실시하였고 세트마다 1 분의 휴식을 주었다.

2) 측정방법

(1) 균형

균형 평가를 위해 위하여 발 압력 분포 측정 시스템(Foot scan, TechStorm Co., Korea)을 이용하였으며, 좌-우, 전-후 균형을 측정하여 측 정값에서 $50 \%$ 뺀 절대값으로 정적 균형의 오차값을 계산하였다.

\section{(2) 기능적 수행 능력}

(1) 한발로 8자 뛰기 검사(Figure-of-8 hop test)

출발점과 반환점에 $5 \mathrm{~m}$ 간격의 콘을 세우고대상자가 한발로 선 후 콘 을 8 자 모양으로 2 바퀴를 돌아오는 시간을 측정하였다. 한발로 8 자 뛰기 검사의 급내상관계수(ICC)는 0.95 이다. ${ }^{9}$

(2) 한발로 위아래 뛰기 검사(Up-down hop test)

대상자가 한발로 선 자세에서 $20 \mathrm{~cm}$ 높이의 상자를 10 회 반복하여 오르내리는 시간을 측정하였다. 한발로 위아래 뛰기 검사의 급내상 관계수(ICC)는 0.95 이다. ${ }^{24}$

\section{(3) 한발로 멀리뛰기 검사(Single hop test)}

대상자가 한발로 출발선에 선 후 정면을 향해 최대한 멀리 뛰도록 지 시하였으며 대상자가 뛴 거리를 줄자로 측정하였다. 측정 시 첫 번째 발가락을 기준으로 측정하였다. 한발로 멀리 뛰기 검사의 급내상관 계수(ICC)는 0.96 이다. ${ }^{25}$

\section{(3) 자료의 분석}

자료의 분석은 SPSS for Windows 18.0 version 통계 프로그램을 이용 하여 분석하였다. 단일과제훈련과 이중과제훈련 후 균형과 기능적 수행능력의 변화는 이원배치 반복측정 분산분석(two-way repeated ANOVA)을 이용하여 시간의 효과, 그룹 간의 비교, 시간과 그룹의 교 호작용을 검정하였다. 시간의 효과가 유의한 경우 전, 후 비교를 위하 여 대응표본 t 검정(paired t-test)을 실시하였으며, 시간과 군의 교호작 용의 유의한 경우 균형과 기능적 수행능력 변화의 그룹 간 차이를 확 인하기 위하여 독립표본 $\mathrm{t}$ 검정(Independent t-test)을 실시하였다. 통계 학적 유의 수준은 $\alpha=0.05$ 로 하였다.

\section{결 과}

\section{1. 연구 대상자들의 일반적 특성}

본 연구 대상자들의 일반적 특성은 다음과 같으며(Table 1), 일반적 특 
성에 대한 그룹 간 유의한차이는 없었다( $\mathrm{p}>0.05)$.

\section{2. 균형의 변화}

전-후 균형의 변화는 이중과제훈련군에서 시간에 따른 유의한 차이 가 있었으며 $(\mathrm{p}<0.05)$, 그룹 간 유의한 차이가 없었다 $(\mathrm{p}>0.05)$. 시간과 그룹 간에 유의한 교호작용이 있었으며 $(\mathrm{p}<0.05)$, 단일과제훈련과 이 중과제훈련의 유의한 차이가 있었다 $(\mathrm{p}<0.05)$ (Table 2). 좌-우 균형의 변화는 시간에 따른 유의한 차이가 없었으며 $(\mathrm{p}>0.05)$, 그룹 간 유의 한 차이 가 없었다 $(\mathrm{p}>0.05)$. 시간과 그룹 간에 유의한 교호작용이 없 었다 $(\mathrm{p}>0.05)$ (Table 2).

\section{3. 기능적 수행 능력의 변화}

한발로 8 자 뛰기 검사는 단일과제훈련군과 이중과제훈련군에서 시 간에 따른 유의한 차이가 있었으며 $(\mathrm{p}<0.001)$, 그룹 간 유의한 차이가 없었다 $(\mathrm{p}>0.05)$. 시간과 그룹 간에 유의한 교호작용이 없었다 $(\mathrm{p}>0.05)$ (Table 3). 한발로 위아래 뛰기 검사는 단일과제훈련군과 이중과제훈 련군에서 시간에 따른 유의한 차이가 있었으며 $(\mathrm{p}<0.001)$, 그룹 간 유 의한 차이가 없었다 $(\mathrm{p}>0.05)$. 시간과 그룹 간에 유의한 교호작용이 있 었으며 $(\mathrm{p}<0.05)$, 단일과제훈련과 이중과제훈련의 유의한 차이가 있었

Table 1. General characteristics of subjects

\begin{tabular}{lcc}
\hline & Single Task & Dual Task \\
\hline Age (year) & $17.8 \pm 1.8$ & $18.5 \pm 4.8$ \\
Height $(\mathrm{cm})$ & $165.5 \pm 5.3$ & $163.3 \pm 9.6$ \\
Weight $(\mathrm{kg})$ & $55.1 \pm 10.3$ & $54.7 \pm 12.2$ \\
Gender $(\mathrm{M} / \mathrm{F})$ & $6 / 3$ & $4 / 6$ \\
\hline
\end{tabular}

다 $(\mathrm{p}<0.05)$ (Table 3). 한발로 멀리뛰기 검사는 시간에 따른 유의한 차 이가 없었으며 $(\mathrm{p}>0.05)$, 그룹 간 유의한 차이가 없었다 $(\mathrm{p}>0.05)$. 시간 과 그룹 간에 유의한 교호작용이 없었다( $\mathrm{p}>0.05)$ (Table 3).

\section{고 찰}

본 연구는 기능적 발목 불안정성이 있는 고등학교 축구 선수 19 명을 대상으로 단일과제훈련과 이중과제훈련이 균형과 기능적 수행능력 에 미치는 영향에 대해 알아보고자 하였다.

균형의 변화는 단일과제훈련군과 이중과제훈련군 모두에서 긍정 적인 향상이 있었다. 전-후 균형 변화에서 그룹 간의 유의한 교호작 용이 있었으며 $(\mathrm{p}<0.05)$, 단일과제훈련과 이중과제훈련의 유의한 차 이가 있었다 $(\mathrm{p}<0.05)$. Shin과 $\mathrm{An}^{26}$ 의 연구에서 이중과제훈련은 단일 과제훈련보다 중년 여성의 균형과 보행 향상에 효과적이었으며, $\mathrm{Hi}-$ yamizu 등 27 의 연구에서 선 자세에서의 이중과제훈련은 단일과제훈 련보다 정상 노인의 균형을 향상시켰다. 이중과제훈련 후 균형 향상 에 대해 Morioka 등 28 은 더 높은 수준의 뇌 기능인 주의와 자각은 서 있는 자세의 조절 능력에 상당한 영향을 미치며, Pellecchia ${ }^{29}$ 는 섬세 한 운동 조절이 필요한 이중과제훈련은 자세 동요가 더 커지게 되나 반복되는 훈련을 통하여 자세 동요가 감소되고 균형 능력이 향상된 다고 하였다. 이처럼 운동과제와 인지과제를 동시에 수행한 이중과제 훈련은 단일과제훈련 보다 자세 조절 능력에 많은 영향을 미치며, 기 능적 발목 불안정성 환자의 균형 향상에 좀 더 효과적인 중재 방법으 로 생각된다.

기능적 수행 능력의 변화는 단일과제훈련군과 이중과제훈련군 모

Table 2. Comparison of balance between pre and post exercises

\begin{tabular}{llccccc}
\hline & & Pre & Post & Time (T) & Group (G) & TxG \\
\hline Anterior-Posterior (\%) & Single task & $9.62 \pm 6.90$ & $9.21 \pm 6.98$ & $0.033^{*}$ & 0.511 & $0.027^{*}$ \\
& Dual task & $13.82 \pm 5.09$ & $9.07 \pm 5.66^{\mathrm{a}, \mathrm{b}}$ & & \multirow{2}{*}{0.209} & 0.772 \\
Medio-Lateral (\%) & Single task & $4.71 \pm 3.43$ & $3.12 \pm 2.30$ & 0.133 & & \\
& Dual task & $3.18 \pm 3.03$ & $2.09 \pm 2.41$ & & \\
\hline
\end{tabular}

Mean \pm S.D., ${ }^{*} \mathrm{p}<0.05$.

aSignificantly different for pre versus post comparison ( $p<0.05)$, bSignificantly different for single task versus dual task on post comparison ( $p<0.05)$.

Table 3. Comparison of functional performance between pre and post exercises

\begin{tabular}{|c|c|c|c|c|c|c|}
\hline & & Pre & Post & Time $(T)$ & Group (G) & $\mathrm{T} \times \mathrm{G}$ \\
\hline \multirow[t]{2}{*}{ Figure-of-8 hop test (sec) } & Single task & $9.92 \pm 0.63$ & $8.47 \pm 0.45^{a}$ & $0.000^{\text {*** }}$ & 0.474 & 0.514 \\
\hline & Dual task & $10.31 \pm 1.36$ & $8.65 \pm 1.30^{\mathrm{a}}$ & & & \\
\hline \multirow[t]{2}{*}{ Up-down hop test (sec) } & Single task & $9.38 \pm 0.72$ & $9.17 \pm 0.80^{\mathrm{a}}$ & $0.000^{\text {***}}$ & 0.898 & $0.021^{*}$ \\
\hline & Dual task & $9.52 \pm 0.67$ & $9.12 \pm 0.74^{\mathrm{a}, \mathrm{b}}$ & & & \\
\hline \multirow[t]{2}{*}{ Single hop test (m) } & Single task & $1.54 \pm 0.13$ & $1.61 \pm 0.17$ & 0.066 & 0.938 & 0.704 \\
\hline & Dual task & $1.55 \pm 0.18$ & $1.59 \pm 0.19$ & & & \\
\hline
\end{tabular}

Mean \pm S.D., ${ }^{*} p<0.05,{ }^{* * *} p<0.001$.

aSignificantly different for pre versus post comparison ( $p<0.05)$, 'Significantly different for single task versus dual task on post comparison ( $p<0.05)$. 
두에서 긍정적인 향상이 있었다. 한발로 위아래 뛰기 검사에서 훈련 후 그룹 간의 유의한 교호 작용이 있었으며 $(\mathrm{p}<0.05)$, 단일과제훈련과 이중과제훈련의 유의한 차이가 있었다 $(\mathrm{p}<0.05)$. Yu와 $\mathrm{Jeon}^{30}$ 의 연구 에서 인지과제와 동시에 수행된 보행 훈련은 일반적인 보행 훈련 보 다 만성 뇌졸중 환자의 보행 능력을 향상시켰으며, Cho와 Lee ${ }^{31}$ 의 연 구에서 이중과제훈련은 뇌종줄 환자의 균형과 보행 능력을 향상시키 며 기능적 활동 증진에 효과적이라고 하였다. Pellecchia ${ }^{32}$ 는 균형과 인 지과제를 동시에 수행한 이중과제훈련은 자세 동요를 감소시키며, Loudon 등 33 은 균형, 고유수용성 훈련, 근력 훈련 등은 기능적 발목 불안정성 환자의 휘청거림(giving-way) 감소, 균형의 안정성과 기능적 능력 향상을 시킨다고 하였다. 이처럼 균형과 인지과제과 동시에 시 행된 이중과제훈련은 단일과제훈련보다 자세 조절에 효과적이며, 자 세 조절 능력의 향상은 기능적 발목 불안정성 환자의 기능적 수행 능 력을 향상시키는 것으로 생각된다.

본 연구와 선행 연구 결과 단일과제훈련과 이중과제훈련 모두에 서 균형의 긍정적인 향상이 있었으며, 본 연구의 결과 이중과제훈련 에서 균형과 기능적 수행 능력의 일부 항목에서 단일과제훈련보다 향상된 결과를 확인하였다. 기존의 단일과제훈련이 균형과 기능적 수행 능력에 향상에 효과적이지만 인지를 포함한 이중과제훈련이 좀 더 긍정적인 개선 효과가 있는 것을 확인하였다. 이에 기능적 발목 불 안정성 환자의 임상적 치료 과정에서 다양한 이중과제 프로그램을 활용한 물리치료적 중재가 필요할 것으로 생각된다.

본 연구는 표본의 크기가 적어 연구의 결과를 일반화하는데 어려 움이 있으며, 단일과제훈련과 이중과제훈련 후 균형과 기능적 수행 능력의 향상을 확인하였으나 그에 따른 상관관계를 확인하지 못한 제한점이 있다. 앞으로 본 연구의 제한점을 보완하여 기능적 발목 불 안정성에 관한 다양한 연구가 필요할 것으로 생각된다.

\section{REFERENCES}

1. Hertel J. Functional anatomy, pathomechanics, and pathophysiology of lateral ankle instability. J Athl Train. 2002;37(4):364-75.

2. Choi HS, Shin WS, Shim JK et al. The relationship between functional movement screen and ankle dysfunctions with chronic ankle instability. J Kor Phys Ther. 2014;26(6):459-63.

3. Ko YM, Jung MS, Park JW. The relationship between strength balance and joint position sense related to ankle joint in healthy women. J Kor Phys Ther. 2011;23(2):23-9.

4. Buchanan AS, Docherty CL, Schrader J. Functional performance testing in participants with functional ankle instability and in a healthy control group. J Athl Train. 2008;43(4):342-6.

5. Lee HJ, Lim KB, Jung TH et al. Changes in balancing ability of athletes with chronic ankle instability after foot orthotics application and rehabilitation exercises. Ann Rehabil Med. 2013;37(4):523-33.
6. Tropp H. Commentary: Functional ankle instability revisited. J Athl Train. 2002;37(4):512-5.

7. Zazulak BT, Hewett TE, Reeves NP et al. Deficits in neuromuscular control of the trunk predict knee injury risk: a prospective biomechanicalepidemiologic study. AmJ Sports Med. 2007;35(7):1123-30.

8. Munn J, Beard DJ, Refshauge KM et al. Do Functional-Performance Tests Detect Impairment in Subjects With Ankle Instability? Journal of sport rehabilitation. 2002;11(1): 40-50.

9. Caffrey E, Docherty CL, Schrader J et al. The ability of 4 single-limb hopping tests to detect functional performance deficits in individuals with functional ankle instability. J Orthop Sports Phys Ther. 2009; 39(11):799-806.

10. Won KH, Lee MG. Effects of adhesive ankle taping on range of motion, proprioception, and functional performance capability in basketball players with functional ankle instability. Exercise Science. 2012;12(1):1122.

11. Docherty CL, Arnold BL, Gansneder BM et al. Functional-performance deficits in volunteers with functional ankle instability. J Athl Train. 2005; 40(1):30-4.

12. Smith BI, Docherty CL, Simon J et al. Ankle strength and force sense after a progressive, 6-week strength-training program in people with functional ankle instability. J Athl Train. 2012;47(3):282.

13. Bae YS, Um KM, Kim NS. The effect of proprioceptive exercise of ankle joint on postural alignment in woman elderly person. J Kor Phys Ther. 2009;21(3):53-60.

14. Mckeon PO, Inqersoll CD, Kerrigan DC et al. Balance training improves function and postural control in those with chronic ankle instability. Med Sci Sports Exerc. 2008;40(10):1810-9.

15. Lim HW. The effect of motor imagery on onset time of leg muscle and ankle injury score of patients with functional ankle instability. J Kor Phys Ther. 2012;24(1);7-14.

16. Sekir U, Yildiz Y, Hazneci B et al. Effect of isokinetic training on strength, functionality and proprioception in athletes with functional ankle instability. Knee Surg Sports Traumatol Arthrosc. 2007;15(5):654-64.

17. Kim MH, Lee JH, Kim CK. The change in postural balance index by kinesio taping and muscle strength exercises on ankle joint. J Kor Phys Ther. 2009;21(3):69-74.

18. Plummer-D'Amato P, Altmann LJ, Saracino D et al. Interactions between cognitive tasks and gait after stroke: a dual task study. Gait Posture. 2008;27(4):683-8.

19. Ross LM, Register-Mihalik JK, Mihalik JP et al. Effects of a single-task versus a dual-task paradigm on cognition and balance in healthy subjects. J Sport Rehabil. 2011;20(3):296-310.

20. Resch JE, May B, Tomporowski PD et al. Balance performance with a cognitive task: A continuation of the dual-task testing paradigm. J Athl Train. 2011;46(2):170-5.

21. Daele UV, Hagman F, Truijen S et al. Decrease in postural sway and trunk stiffness during cognitive dual-task in nonspecific chronic low back pain patients, performance compared to healthy control subjects. Spine. 2010;35(5):583-9.

22. Docherty CL, Gansneder BM, Arnold BL et al. Development and reliability of the ankle instability instrument. J Athl Train. 2006;41(2):154-8.

23. Prentice WE. Rehabilitation techniques for sports medicine and athletic training (5th ed.)., New York: McGraw-Hill. 2011:184-5. 
24. Ortiz A, Olson S, Libby CL et al. Kinematic and kinetic reliability of two jumping and landing physical performance tasks in young adult women. N Am J Sports Phys Ther. 2007;2(2):102-4.

25. Bolgla LA, Keskula DR. Reliability of lower extremity functional performance tests. J Orthop Sports Phys Ther. 1997;26(3):138-42.

26. Shin SS, An DH. The effect of motor dual-task balance training on balance and gait of elderly women. J Phys Ther Sci. 2014;26(3):359-61.

27. Hiyamizu M, Morioka S, Shomoto K et al. Effects of dual task balance training on dual task performance in elderly people: A randomized controlled trial. Clin Rehabil. 2012;26(1):58-67.

28. Morioka S, Hiyamizu M, Yagi F. The effects of an attentional demand tasks on standing posture control. J Physiol Anthropol Appl Human Sci. 2005; 24(3):215-9.
29. Pellecchia GL. Postural sway increases with attentional demands of concurrent cognitive task. Gait Posture. 2003;18(1):29-34.

30. Yu KH, Jeon JS. The effects of dual-task gait training on gait performance under cognitive tasks in chronic stroke. J Kor Phys Ther. 2015;27(5):364-8.

31. Cho KH, Lee WH. The effects of two motor dual task training on balance and gait in patients with chronic stroke. J Kor Phys Ther. 2010; 22(4):7-14.

32. Pellecchia GL. Dual-task training reduces impact of cognitive task on postural sway. J Mot Behav. 2005;37(3):239-46.

33. Loudon JK, Santos MJ, Franks L et al. The effectiveness of active exercise as an intervention for functional ankle instability: A systematic review. Sports Med. 2008;38(7):553-63. 